DANIELY VASCONCELOS SOARES

\title{
HALITOSE EM PACIENTE COM DEFICIÊNCIA INTELECTUAL- RELATO DE CASO
}

\begin{abstract}
Trabalho de Conclusão de Curso apresentado como requisito para aprovação da disciplina TCC II do Curso de Graduação em Odontologia da Universidade Luterana do Brasil - ULBRA, Campus Torres.
\end{abstract}

Orientadora: Prof. Esp. Gilceany Vilar Almeida 
Aos meus pais e minha irmã que, com muita garra e fé, lutaram para que eu pudesse realizar esse sonho e sempre estiveram ao meu lado nessa caminhada. Aos meus amigos(as) que, acreditaram em mim e me apoiaram o tempo todo. Dedico a vocês este trabalho. 


\section{RESUMO}

A halitose é um odor desagradável emanado pela boca, de causas multifatoriais e por isso, não tem um tratamento especifico. Pode ser causada por doenças orais ou sistêmicas, mas a maioria dos casos tem origem oral, onde a saburra lingual e a placa bacteriana são as causas mais comuns. Nesse contexto, um paciente com deficiência intelectual, 50 anos, acompanhado de seu pai, compareceu à Clínica Escola da Universidade Luterana do Brasil - Campus Torres/RS com a queixa de mau hálito constante e perda de dentes causada pela doença periodontal, e que o mau cheiro bucal estava atrapalhando na convivência familiar. O objetivo deste trabalho é relatar, por meio de caso clínico, o tratamento odontológico realizado neste paciente com deficiência intelectual, na clínica mencionada. Foi elaborado um plano de tratamento para ser realizado em etapas, contendo medidas de promoção de saúde oral para obter-se uma adequação do meio bucal, conscientizando o paciente e seus pais da importância da higiene oral, juntamente com o tratamento da doença periodontal e halitose. Os profissionais devem ser melhor preparados quanto ao atendimento integral e psicossomático do paciente e saber identificar os fatores fisiológicos e patológicos da halitose, a fim de prevenir seus efeitos deletérios, entre eles, o prejuízo na qualidade de vida e relacionamento interpessoal do indivíduo com mau hálito.

Palavras-chave: Halitose; Paciente com necessidade especial; Odontologia 


\begin{abstract}
Halitosis is an unpleasant smell emanated by the mouth, of multifactorial causes and, because of that, it doesnt have a specific treatment. It can be caused by oral or systemic diseases, but the majority of the cases has oral origin, which tongue coating and bacterial plaque are the most common causes. In this context, a patient with intellectual disability, 50 years old, accompanied by his father, attended the Clinic School of Lutheran University of Brazil - Campus Torres/RS complaining of constant bad breath and teeth loss caused by periodontal disease and the bad breath was disturbing his family living. The objective of this project is to report, through a clinical case, the odontological treatment realized in this patient with intelectual disability, in the clinic previously mentioned. A treatment plan was elaborated to be carried out in stages, containing oral health promotion measures, to achieve an adequate oral environment, making the patient and his parents aware of the importance of oral hygiene along with the treatment of periodontal disease and halitosis. The professionals involved should be better prepared about the comprehensive and psychosomatic patient care and to identify the physiological and pathological factors of halitosis, in order to prevent its deleterious effects, the injury in quality of life and interpersonal relationship of the individual with bad breath.
\end{abstract}

Key words: Halitosis; Special Need Patient; Odontology. 


\section{LISTA DE ILUSTRAÇÕES}

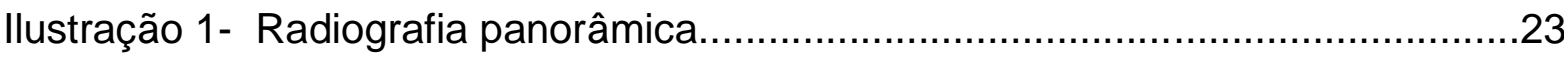

Ilustração 2- Dentes anteriores superiores apinhados.........................................24

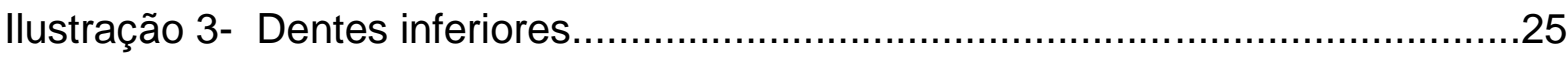

llustração 4- Dentes anteriores superiores na $18^{\circ}$ consulta....................................26

llustração 5- Dentes inferiores na $18^{\circ}$ consulta..................................................27

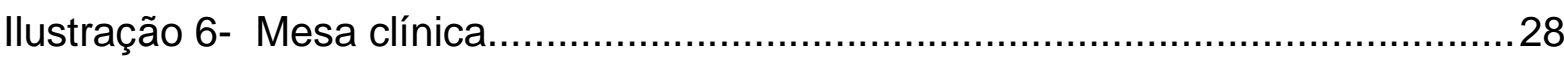

llustração 7- Escovas dentais fornecidas para o paciente.......................................29 


\section{LISTA DE ABREVIATURAS E SIGLAS}

CSV Compostos sulfurados voláteis

PPNE Paciente Portador de Necessidade Especial

PNE Paciente com Necessidade Especial

BANA Método enzimático Benzoyl-arginine-naphtylamida

RAP Raspagem Supragengival

RASUB Raspagem Subgengival

IPV Índice de Placa Visível

ISG Índice de Sangramento Gengival

PS Profundidade à Sondagem

PI Perda de Inserção 
SUMÁRIO

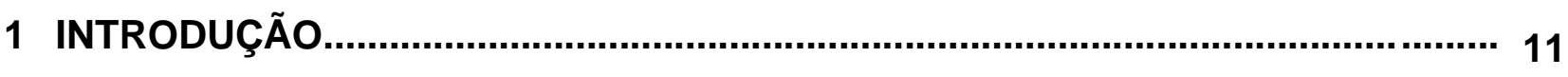

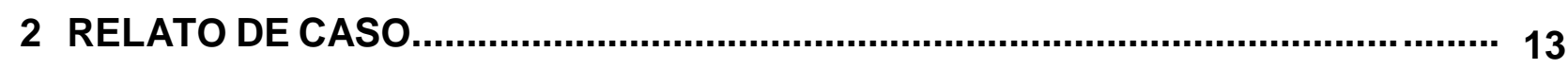

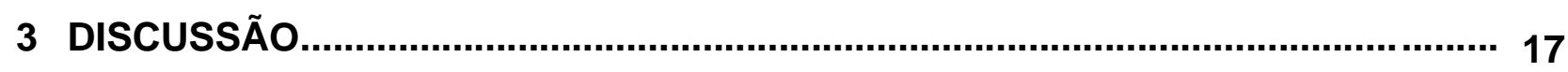

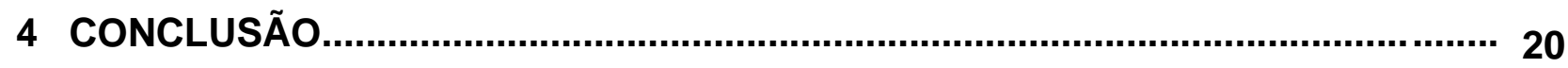

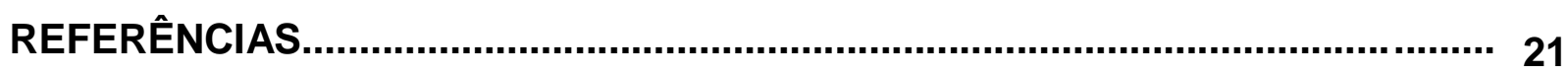

APÊNDICE A- ILUSTRAÇÕES................................................................. 23 


\section{INTRODUÇÃO}

Os pacientes portadores de necessidades especiais ou PPNE são todos os indivíduos adultos ou crianças, que se desviam física, intelectual, social ou emocionalmente daquilo que é considerado normal em relação aos padrões de crescimento e desenvolvimento e, por isso, requerem educação especial e instrução suplementar em serviços adequados, durante um período, ou por toda sua vida[1]. Para realizar o tratamento odontológico em pacientes especiais existem dificuldades que devem ser superadas, como por exemplo: as dificuldades motoras, dificuldades devido à falta de comunicação, sialorréia, macroglossia, o apinhamento dental, falta de compreensão da família desses pacientes em relação à importância do tratamento e da remoção diária da placa dental, entre outras[2]. Geralmente, os PNEs apresentam maior prevalência da doença cárie, mais dentes não tratados e maior número de dentes perdidos, além de possuírem maior necessidade de tratamento periodontal, ocasionando a presença da halitose, originada principalmente pelo acúmulo de placa bacteriana e sangramento gengival[1].

A halitose, do latim halitus, que significa hálito, é uma queixa bem comum encontrada principalmente em adultos[3]. Afeta aproximadamente $40 \%$ da população brasileira e pode ser causada por doenças orais ou sistêmicas, mas a maioria dos casos tem origem oral e a saburra lingual está presente em cerca de $90 \%$ deles[4]. Constitui um problema de saúde pública em razão do grande número de pessoas atingidas e da dificuldade de diagnóstico devido a causas multifatoriais[5]. É uma condição em que o hálito se apresenta de forma desagradável, podendo ser emanado pela boca, pelas cavidades nasais, pelos seios da face e pela faringe[6,7], quando persistente pode indicar desordens orais, tais como doença periodontal, língua saburrosa, processos cariosos, placa bacteriana, alterações morfológicas da língua, gengivite, feridas cirúrgicas, alveolite e pericoronarite[4]. Podendo ser causada também, por doenças otorrinolaringológicas e respiratórias como a faringite, amigdalite, sinusite, bronquite, por doenças do sistema digestivo como síndromes de má absorção e doença de refluxo gastroesofágico, halitofobia e diabetes mellitus[ $[7,8]$. 
A halitose pode ser classificada como genuína, pseudo-halitose e halitofobia. A halitose genuína é subclassificada como fisiológica ou patológica[9].

Além de uma boa anamnese e exames clínicos, existem três formas de avaliação e diagnóstico da halitose: o teste BANA, organoléptico e halitometria.

Devido à etiologia multifatorial da halitose, não existe terapêutica padrão para o seu tratamento. A avaliação geral da saúde do indivíduo fornecerá subsídios para requisição de exames complementares, bem como para a necessidade de uma abordagem transdisciplinar. A maior parte dos tratamentos consiste em intervenções mecânicas e químicas no cavidade bucal. Especificamente, as intervenções mecânicas são a intensificação da escovação, o uso do fio dental, a raspagem da superfície lingual, enxaguatório bucal e o uso de creme dental contendo sais de zinco[10,11]. Os sais de zinco são os agentes químicos mais utilizados no controle da halitose, pois inibem a volatilização dos compostos ricos em enxofre que são liberados pelas bactérias[12].

Os profissionais devem ser capazes de identificar os fatores fisiológicos e patológicos da halitose, a fim de prevenir seus efeitos deletérios, entre eles, o prejuízo na qualidade de vida e relacionamento interpessoal do indivíduo com o mau hálito[13]. Assim, tendo em vista esses motivos e visando contribuir, o presente trabalho relata o caso clínico de um tratamento odontológico realizado em um paciente portador de deficiência intelectual com halitose. 


\section{RELATO DE CASO}

A deficiência intelectual é a incapacidade caracterizada por limitações significativas tanto intelectual quanto com habilidades conceituais, sociais e práticas. Para tanto, o mesmo foi submetido e aprovado pelo Comitê de Ética e Pesquisa em Seres Humanos da ULBRA.

Paciente VGNS, gênero masculino de 50 anos de idade, portador de deficiência intelectual, procurou o atendimento da clínica odontológica da ULBRA-Campus Torres acompanhado pelo seu pai, com a queixa de mau hálito severo e perda de dentes. Seu pai relatou que a convivência e proximidade com seu filho estava prejudicada devido ao cheiro desagradável emanado pela boca. Após exames iniciais foi diagnosticado doença periodontal crônica generalizada e com a queixa de mau hálito constante, foi constatado que o paciente possui halitose. O paciente possui em boca os elementos 11, 12, 13, 14, 15, 21, 22, 23, 24, 25, 26, 33, 34, 35, 37, 43, 44, 45, 47 hígido (Ilustração 1, pg.23), com mobilidade moderada e os incisivos superiores apinhados (llustração 2, pg.24), os outros elementos são ausentes por extração ou por outro motivo. Conforme o exame clínico, apresentou placa visível e sangramento gengival em todos os elementos, bolsas periodontais de até $5 \mathrm{~mm}$ e perda de inserção de até $9 \mathrm{~mm}$.

Devido a deficiência na motricidade e falta de interesse, notou-se a dificuldade de higienização oral, com visível acúmulo de placa bacteriana nos dentes e língua, doença periodontal avançada, o que leva ao diagnóstico de halitose patológica devido a soma desses fatores, juntamente com o teste organoléptico complementar. O paciente é portador de Diabetes Mellitus tipo 2, faz uso de medicação para a mesma e de Ácido acetilsalicílico (AAS), pois aproximadamente 10 anos atrás teve uma suspeita de infarto, permanecendo no hospital por 20 dias.

Mediante o diagnóstico, foi planejado para o tratamento: instruções de higiene bucal e incentivo para a sua realização, raspagens supra gengivais com curetas periodontais e ultrassom, raspagens sub gengivais com limas periodontais, para que assim o acúmulo de placa e sangramento diminuam, e consequentemente, melhore a saúde periodontal e a intensidade do mau hálito. 
$1^{\underline{a}}$ consulta: Foram realizados profilaxia e instruções de higiene bucal. Foi prescrito digluconato de clorexidina $0,12 \%$ por 7 dias para auxiliar na higiene oral, pois havia acúmulo de placa bacteriana e sangramento em todos os elementos. O paciente apresentava halitose severa.

$2^{\mathrm{a}}$ consulta: Foram feitas RAP e RASUB do $1^{\circ}, 2^{\circ}$ e $3^{\circ}$ sextante, profilaxia e instruções de higiene bucal.

$3^{\text {a }}$ consulta: Foi realizada RAP do $1^{\circ}, 2^{\circ}$ e 3 sextante novamente porque a placa bacteriana já estava mineralizada e só a profilaxia não a removeria, realizando profilaxia e instruções de higiene bucal também. O paciente relatou que fazia dias que não escovava os dentes, relatando não saber o motivo ou por preguiça.

4a consulta: Foram realizadas RAP e RASUB do $4^{\circ}$ e $6^{\circ}$ sextante, profilaxia e instruções de higiene bucal. Foi prescrito digluconato de clorexidina 0,12\% por 7 dias para tentar uma melhora na condição bucal e para ter mais um auxilio além da escovação. O paciente continuava sem escovar os dentes em casa. Foi solicitado a presença dos pais na próxima consulta.

5 consulta: Foram feitos IPV e ISG, RAP e RASUB do $1^{\circ}$ sextante, profilaxia e instruções de higiene bucal. Paciente continuava sem escovar os dentes e solicitando-a a presença dos pais novamente, pois não compareceram, para conversar sobre a importância da higiene bucal e que o ajudassem em casa. O paciente estava utilizando a clorexidina em livre demanda, camuflando a real condição da doença periodontal, solicitando que parasse o uso e optando por não prescrever mais.

$6^{\mathrm{a}}, 7^{\mathrm{a}}, 8^{\mathrm{a}}, 9^{\mathrm{a}}$ consulta: Essas consultas serviram basicamente para instruir o paciente sobre a higiene bucal, fazê-lo entender da importância dela para que o tratamento evoluísse. Foi explicado para os pais o que era a doença periodontal e a halitose, e que eles poderiam ajudar e incentivar na escovação em casa. Halitose continuava severa.

$10^{\mathrm{a}}, 11^{\mathrm{a}}, 12^{\mathrm{a}}$ consulta: Foram realizados IPV, ISG, PS, PI, profilaxia, instruções de higiene bucal, RAP de todos os sextantes para remover placa bacteriana que já estavam em processo de mineralização em alguns elementos, 
constatou-se visível melhora da escovação, diminuição de placa bacteriana, de sangramento gengival e do mau hálito. $O$ pai relatou que foi significativa a melhora em relação ao mau hálito.

$13^{\text {a }}$ consulta (realizada após 2 meses): Foram realizados IPV, ISG, PS, $\mathrm{PI}$, profilaxia e instruções de higiene bucal. Era visível o retrocesso em relação a higiene bucal e consequentemente ao tratamento da doença periodontal e halitose.

$14^{\mathrm{a}}, 15^{\mathrm{a}}, 16^{\mathrm{a}}, 17^{\mathrm{a}}$ consulta: Foram realizadas RAP e RASUB de todos os sextantes, profilaxia e instruções de higiene bucal. Sempre conversando e explicando para o paciente a importância da higiene bucal em casa, para que o tratamento volte a evoluir. Acúmulo de placa, sangramento gengival e mau hálito presente. Foi solicitada a presença dos pais na consulta seguinte, para pedir auxílio na realização da higiene oral em casa.

18 $8^{\text {a consulta: }}$ O IPV e ISG nos dentes superiores diminuiu significativamente, já nos dentes inferiores havia presença de sangramento gengival, optando por realizar RAP e RASUB, profilaxia e IHB. É notória a melhora da higiene oral quando é solicitada a presença dos pais na consulta, devido ao respeito e obediência que tem pelo pai (llustração 4 e 5, pg. 26 e 27), optando por sempre solicitar a presença do pai nas consultas.

19a consulta: O IPV e ISG continua diminuindo significativamente. Nos dentes inferiores foi realizado novamente RAP e RASUB, por ter acúmulo de placa bacteriana em processo de mineralização e sangramento gengival. $O$ pai estava presente na consulta e relatou que não há mais a presença do mau hálito.

Durante os atendimentos, o paciente mantinha-se calado e inseguro, concordando com poucas palavras ou sinais com a cabeça, contudo, a comunicação com o paciente esteve sempre presente, tentando assim adquirir confiança e deixando-o mais seguro. O paciente começou a conversar depois de mais ou menos dez consultas. Chegava sempre sorrindo e feliz por estar ali, já conseguia contar mais sobre a sua vida e o que fazia durantes os dias, inclusive relatando saudades dos atendimentos, mostrando assim a sensação de bemestar. 
Nesses meses de tratamento, viu-se a dificuldade do paciente para se comunicar, por isso foi encaminhado ao projeto Sorrir para a Vida-PNE na Ulbra Torres. Em nenhum momento os pais afirmaram ser ele uma pessoa portadora de necessidade especial, era visível a negação dos pais em relação à deficiência intelectual presente. Em algumas consultas onde o pai estava presente, contou que VGNS desde pequeno teve dificuldade na fala e de entendimento, e que o incentivava com a leitura de livros para melhorar a comunicação, ele sempre ficou em casa para ajudar a mãe a cuidar do irmão que também é portador de necessidade especial. VGNS frequenta um grupo no CAPS onde fazem atividades e caminhadas, para que ele tenha convivência com outras pessoas. O pai sempre o elogia muito a por ser carinhoso, disposto a ajudar e pela dedicação que tem com o irmão.

O objetivo principal do tratamento, além de tratar a halitose causada pela doença periodontal, é conscientizar e orientar o paciente sobre a adequada higiene bucal, trazendo de volta a saúde e restabelecendo assim o convívio harmonioso familiar e sensação de bem-estar. 


\section{DISCUSSÃO}

Os odores desagradáveis provenientes da cavidade oral resultam da produção de CSV e compostos orgânicos voláteis de origem putrefativa, por ação das bactérias gram-negativas anaeróbias da microbiota bucal sobre aminoácidos que contêm enxofre. O mau hálito matinal ou halitose fisiológica, por exemplo, ocorre devido à diminuição do fluxo salivar durante o sono e consequente acúmulo e putrefação de células epiteliais descamadas pelas bactérias e restos de alimento, o qual desaparece após a higienização oral pela manhã e com o restabelecimento do fluxo salivar aos valores normais[5,14]. Já a halitose patológica pode ser dividida em intra ou extra bucal, de acordo com o seu local de origem, pacientes podem apresentar mau odor proveniente apenas da cavidade oral ou apenas da cavidade nasal, e podendo também ter origem bucal e nasal simultaneamente[14]. Caso o mau cheiro oral não exista, mas o paciente acredita que tem o mau odor, o diagnóstico seria pseudo-halitose. Se, após o tratamento para halitose patológica ou pseudo-halitose, o paciente ainda acredita que tem mau hálito, o diagnóstico seria halitofobia. Esta classificação permite ao clínico diagnosticar uma condição psicológica[9].

O diagnóstico da halitose patológica foi feito através da anamnese, exames orais e teste complementar organoléptico. O paciente possui doença periodontal, dentes apinhados que favorecem o acúmulo de placa bacteriana, saburra lingual, sangramento gengival, diabetes tipo 2 e toma medicamentos para a mesma, fatores estes que são causas da halitose.

O teste organoléptico é de utilidade limitada, pois depende da capacidade olfatória do examinador. $O$ teste deve ser realizado quando o paciente sentir que o mau hálito está mais severo, e consiste em respirar profundamente pelas narinas e expirar pela boca, enquanto o examinador avalia 0 ar expirado colocando-se a uma distância de aproximadamente $20 \mathrm{~cm}$ do paciente e considera, desagradável ou não em uma escala de 0 a 10[7]. A halitometria é feita através de um aparelho chamado halímetro, que analisa o ar expirado pelo paciente, baseada em tecnologia de semicondutores para mensuração de CSV e gases hidrocarbonetos, permitindo análise do hálito em cinco segundos, de forma a classificá-lo em seis níveis de acordo com a quantidade desses gases[6]. O teste BANA é um instrumento prático para avaliar a proliferação bacteriana 
no sulco gengival, e sua positividade está fortemente relacionada a doenças periodontais[7]. O teste consiste em tiras de papel especial onde são colocadas amostras de saburra ou conteúdo de material periodontal que sofrem reação enzimática ativando um corante que indica a presença de alta concentração de bactérias produtoras de CSV, esse teste pode ser complementar ao halímetro[15].

Pacientes especiais acabam precisando de atenção integral dos pais ou cuidadores para atividades diárias, incluindo a higiene oral, tanto pela dificuldade de execução, quanto pela falta de entendimento do porquê realizá-la e, devido a essa dificuldade, acabam surgindo cáries, gengivite, doença periodontal e halitose, por exemplo.

A criança ou adulto com deficiência intelectual tem as funções intelectuais abaixo dos padrões normais para sua idade e está associada à perda ou dificuldade de aprendizado e adaptação social[16]. A alta prevalência de desordens bucais pode estar associada às limitações decorrentes da deficiência, ao consumo frequente e regular de alimentos ricos em sacarose, ao uso de medicação contínua, ao alto custo do tratamento especializado, à escassez de profissionais habilitados para a realização do atendimento, à condição socioeconômica familiar, à dificuldade dos pacientes e dos cuidadores na realização e manutenção da higiene bucal. A qualidade da higiene bucal está diretamente relacionada ao quadro clínico do paciente, sendo que indivíduos com problemas de motricidade e inteligência apresentam, de modo geral, higiene bucal comprometida[1].

A necessidade de uma relação especial e de confiança entre o profissional e os pacientes, no sentido de minimizar situações ameaçadoras e estressantes, é de suma importância. Apenas o conhecimento científico e a habilidade técnica não são suficientes, uma vez que cada paciente é único e especial, por exibir graus diferentes de condições de saúde e diferentes dificuldades para se adequar a certas situações[17].

A relação dentista-paciente é um dos pontos mais importantes e difíceis para o sucesso do tratamento odontológico, porque é construída aos poucos durante as consultas. Através da comunicação e da explicação de cada passo durante o tratamento, essa relação de confiança foi se criando ao longo do 
tempo, fazendo com que o paciente se sentisse mais à vontade $\mathrm{e}$ compreendendo a importância de estar ali. A presença do pai nas consultas foi imprescindível para que essa relação existisse, pois em todo o momento o pai ressaltava a importância da higiene oral, o quanto a saúde bucal era importante e mostrava-se orgulhoso pelo seu filho estar dedicado ao tratamento, e com esse incentivo familiar era visível que o paciente se motivava e queria mostrar que estava fazendo sua parte em casa para que o tratamento evoluísse.

A família tem um papel crucial na vida destas pessoas, muitas vezes, são os primeiros a verificar a necessidade de tratamento dentário e podem ser também peças chave para a comunicação e criação de uma boa relação dentista-paciente na consulta odontológica. Além das informações relevantes para a história clínica, os familiares também podem fornecer informações sobre o paciente, que nos ajudam a melhorar a forma de lidar com esse[18].

Segundo relato do pai, ele sempre se preocupou com a higiene oral, porém seu filho não o deixava ajudar: " quando ele era pequeno não deixava eu encostar para ajudar na escovação, sempre foi teimoso. O tempo acabou passando e tínhamos o irmão especial dele pra ajudar também, só que não dava mais para adiar, o mau hálito e a perda de dentes piorou muito. Hoje, às vezes eu cobro a escovação, mas meu filho está dedicando um tempo em casa para escovar os dentes, ele está entendendo que é importante para ele e para nós da família, porque o mau hálito estava atrapalhando muito."

O ato de cuidar do PNE pressupõe a execução de atividades diversas. Considerando o grau de dependência da pessoa que recebe o cuidado, a demanda vai desde cuidados básicos com a higiene e alimentação até outros mais complexos, como sondagem e cuidados com dispositivos de saúde[19]. 


\section{CONCLUSÃO}

Nesse relato vimos a dificuldade que o PPNE tem para compreender e realizar a higiene oral; na maioria dos casos necessita de assistência e incentivo dos pais ou de um cuidador, porque o paciente sozinho não se motiva a realizála.

A halitose tem causas multifatoriais e quando essas são diagnosticadas corretamente pode ser tratada de forma simples, com recursos mecânicos e químicos, sendo a escovação o principal meio para eliminar o mau odor oral. 0 apinhamento dental e a doença periodontal são fatores que acabam dificultando o tratamento da halitose, porém o tratamento da doença periodontal juntamente com instruções de higiene oral, utilizando recursos auxiliares (escovas interdentais, fio dental, dentifrícios, enxaguatórios bucais) (Ilustração 7, pg.29), resultaram satisfatoriamente na diminuição do mau hálito.

Assim como qualquer pessoa, esse paciente possui suas individualidades, medos, traumas, sentimentos e preferências. Junto a essa pessoa, existe também, uma família especial que passa por obstáculos dia a dia pra dar a melhor condição de vida ao filho. O Cirurgião-dentista deve enxergar o PNE como um indivíduo completo, dispondo de toda atenção e dedicação necessárias para esse paciente, melhorando tanto a sua qualidade de vida, quanto a da família, que é o seu alicerce. 


\section{REFERÊNCIAS}

1. Hartwig AD, Junior IFS, Stüermer VM, Schardosim LR, Azevedo MS. Recursos e técnicas para a higiene bucal de pacientes com necessidades especiais. Revista da AcBO-ISSN 2015. 4(3): 2316-7262.

2. Sampaio EF, César FN, Martins MDGA. Perfil odontológico dos pacientes portadores de necessidades especiais atendidos no Instituto de Previdência do Estado do Ceará. Revista Brasileira em Promoção da Saúde 2012. 17(3): 127-134.

3. Crispian S. Boletim: Halitose (mau hálito). In: Crispian S. Medicina oral e maxilofacial: Bases do diagnóstico e tratamento. 2. ed. Rio de Janeiro: Elsevier; 2008. p. 87-91.

4. Vasconcelos S, Veloso DJ, Cunha PÂS, Vasconcelos LCD. Clinical knowledge of dentists and physicians on the diagnosis and treatment of the patient complaining of halitosis. Revista Odonto Ciência 2011. 26(3): 232-237.

5. Calil CM, Tarzia O, Marcondes FK. Qual é a origem do mau hálito?. Rev Odontol UNESP 2006. 35(3): 185-90.

6. Leandrin TP, Boeck EM, Ricci HA, Andrade MF, Leite JBBC. Avaliação da percepção pessoal em relação à condição de halitose e confirmação clínica. Rev Odontol UNESP 2015. 6: 299-304.

7. Dal Rio ACC, Nicola EMD, Teixeira ARF. Halitose: proposta de um protocolo de avaliação. Rev Bras Otorrinolaringol 2007. 73(6): 835-42.

8. Ferreira JFA. Halitose: da etiologia ao tratamento (Doctoral dissertation) [acesso em: 16 set. 2019]. Porto: Universidade Fernando Pessoa Faculdade Ciências da Saúde; 2016. Disponível em: https://bdigital.ufp.pt/bitstream/10284/5604/1/PPG_\%2023469.pdf

9. Yaegaki K, Coil JM. Examination, classification, and treatment of halitosis; clinical perspectives. Journal-canadian dental association 2000. 66(5): 257-261.

10. Silva FLD. Esquiva social e medo de avaliação negativa em pacientes portadores de halitose: estudo de intervenção. (Monografia) [acesso em: 24 maio 2019]. Salvador: Universidade Federal da Bahia; 2017. Disponível em: https://repositorio.ufba.br/ri/handle/ri/21375. 
11. Carvalho MFD, Rodrigues PA, Chaves MDGAM. Halitose: revisão literária. HU rev 2008. 34(4): 273-279.

12. Hoffmann $\mathrm{CH}$. Dentifrícios em periodontia. (Monografia) [acesso em: 15 jun. 2019]. Florianópolis: Universidade Federal de Santa Catarina, 2008. Disponível em: http://tcc.bu.ufsc.br/Espodonto281462.PDF.

13. Domingos PADS, Abreu AC, Dantas AAR, Oliveira ALBMD. Halitose: limitando a qualidade de vida. Revista de Odontologia da Universidade Cidade de São Paulo 2011. 171-181.

14. Fagundes BO. Halitose, uma abordagem dos fatores locais: saburra lingual e doença periodontal. Repositório São Lucas 2017.

15. Salis AMVD, Toledo BECD, Zuza EP, Figueiredo LCD. A aplicabilidade de teste de BANA no consultório odontológico. RGO 2003. 51(5): 429434.

16. Marra PS. Dificuldades encontradas pelos responsáveis, para manter a saúde bucal em portadores de necessidades especiais. (Dissertação) [acesso em: 15 set. 2019]. Duque de Caxias: Universidade do Grande Rio "Prof. José de Souza Herdy", 2007. Disponível em: http://tede.unigranrio.edu.br/bitstream/tede/102/5/Pinkie\%20Seabra\%20 Marra.pdf

17. Santos B, Aquino D, Souza FP, Almeida G, Garcia L. Assistência odontológica a portadores de necessidades especiais sob a ótica dos cuidadores. Brazilian Dental Science 2009. 12(2).

18. Louro CSPOC. Determinantes e prevalência de doenças orais e comportamentos de saúde oral em pacientes com necessidades especiais. (Dissertação) [acesso em: 10 set. 2019]. Viseu: Universidade Católica Portuguesa, 2015. Disponível em:

https://repositorio.ucp.pt/bitstream/10400.14/18710/1/Carolina\%20Lourofinal\%202.pdf

19. Pereira CM, Castro CEB, Sá PFG. Importância do conhecimento sobre saúde bucal dos cuidadores de pacientes com necessidades especiais. Revista da Faculdade de Odontologia de Lins 2019. 29(1): 312. 


\section{APÊNDICE A}

Ilustração 1- Radiografia panorâmica

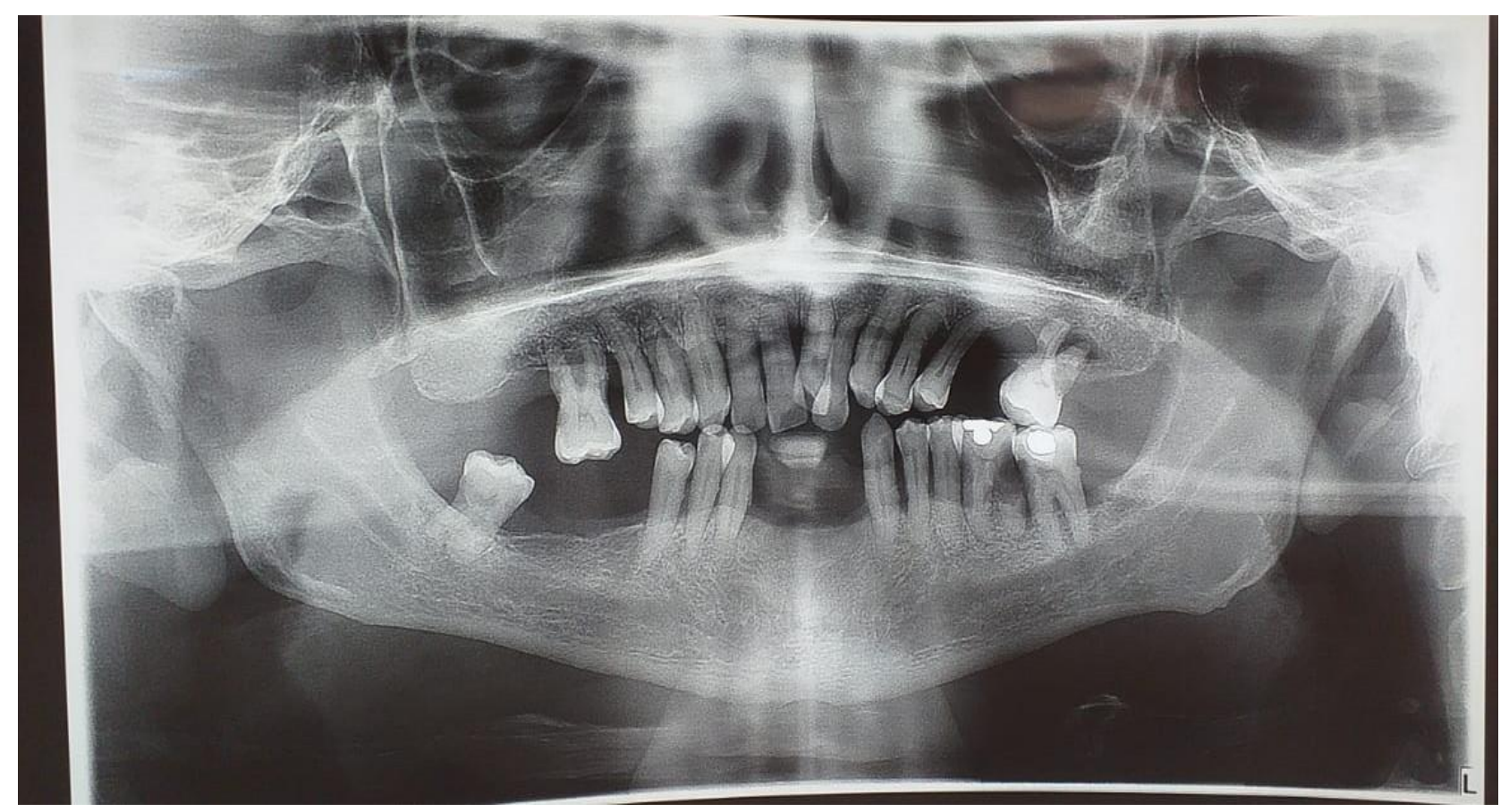

Fonte: Acervo do autor. 
llustração 2- Dentes anteriores superiores apinhados

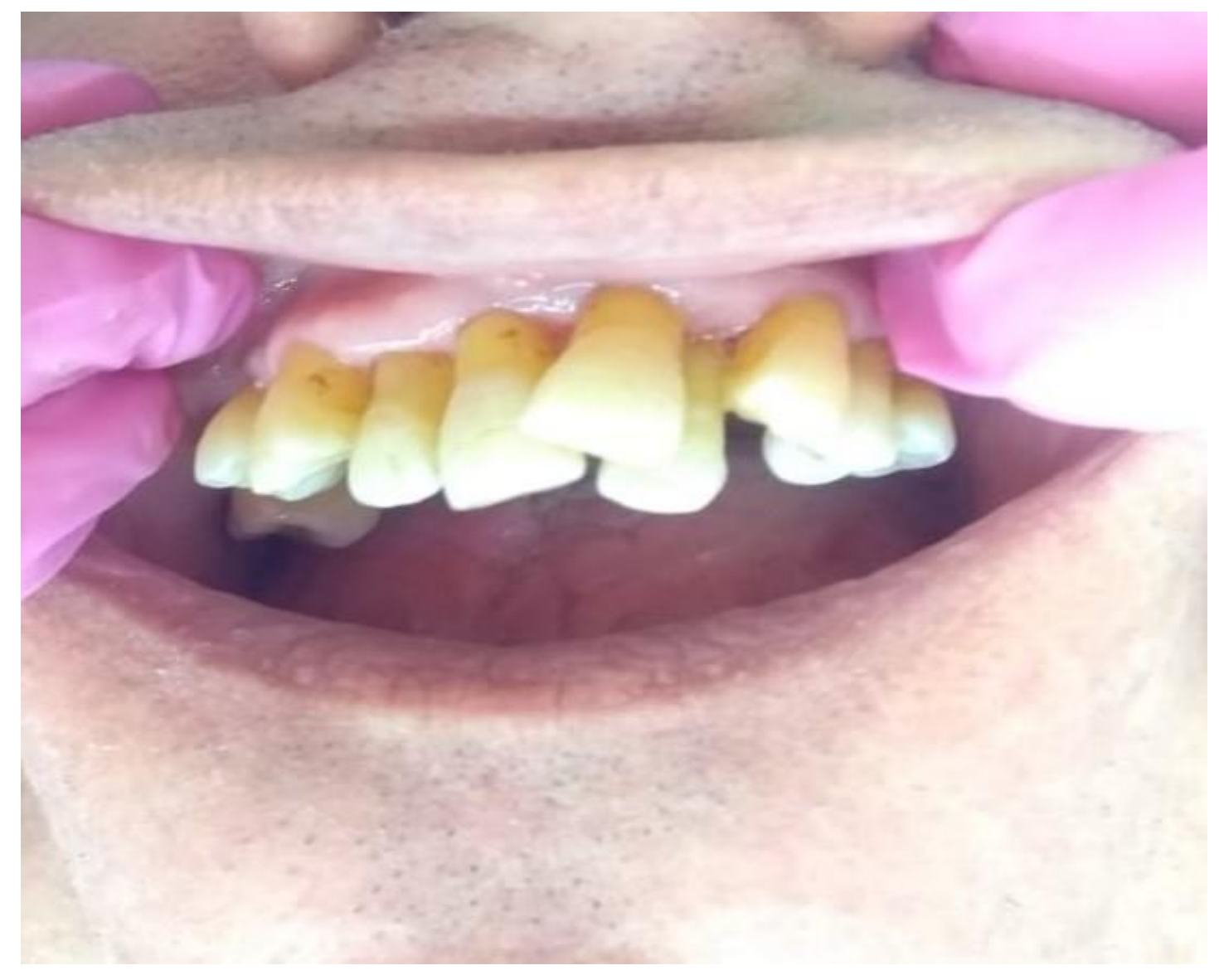

Fonte: Acervo do autor. 
llustração 3- Dentes inferiores

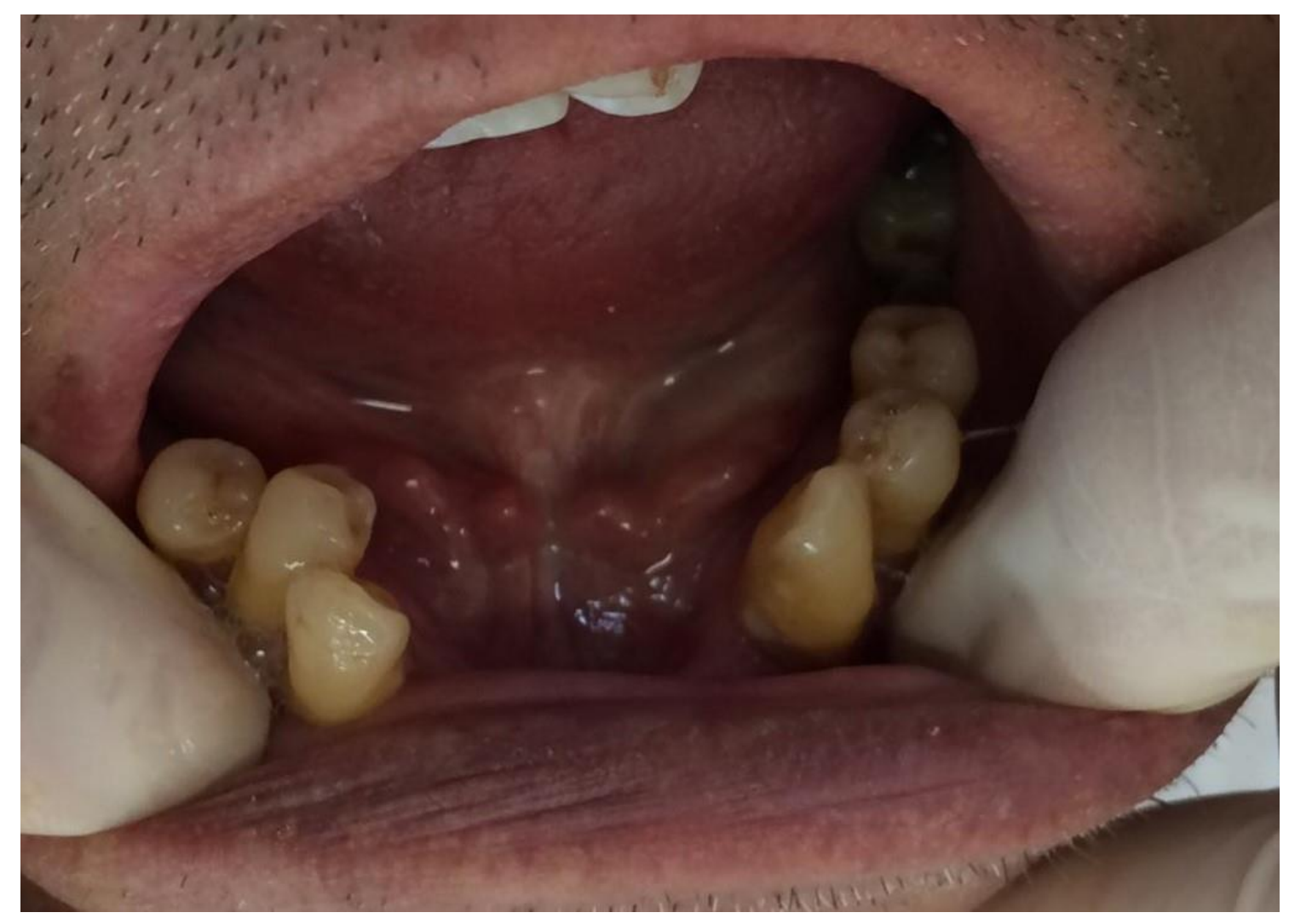

Fonte: Acervo do autor. 
llustração 4- Dentes superiores anteriores na $18^{\circ}$ consulta

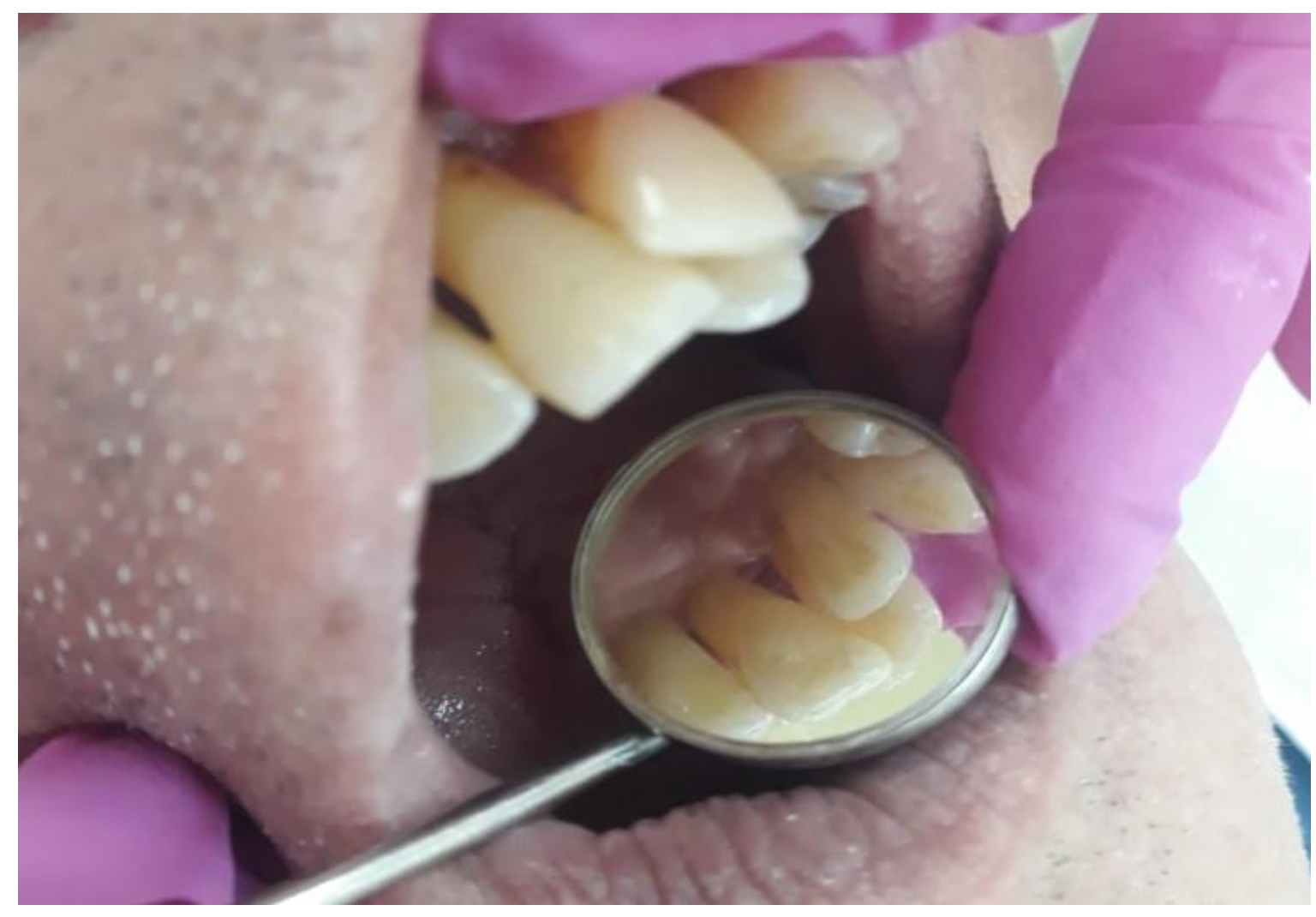

Fonte: Acervo do autor. 
Ilustração 5- Dentes inferiores na $18^{\circ}$ consulta

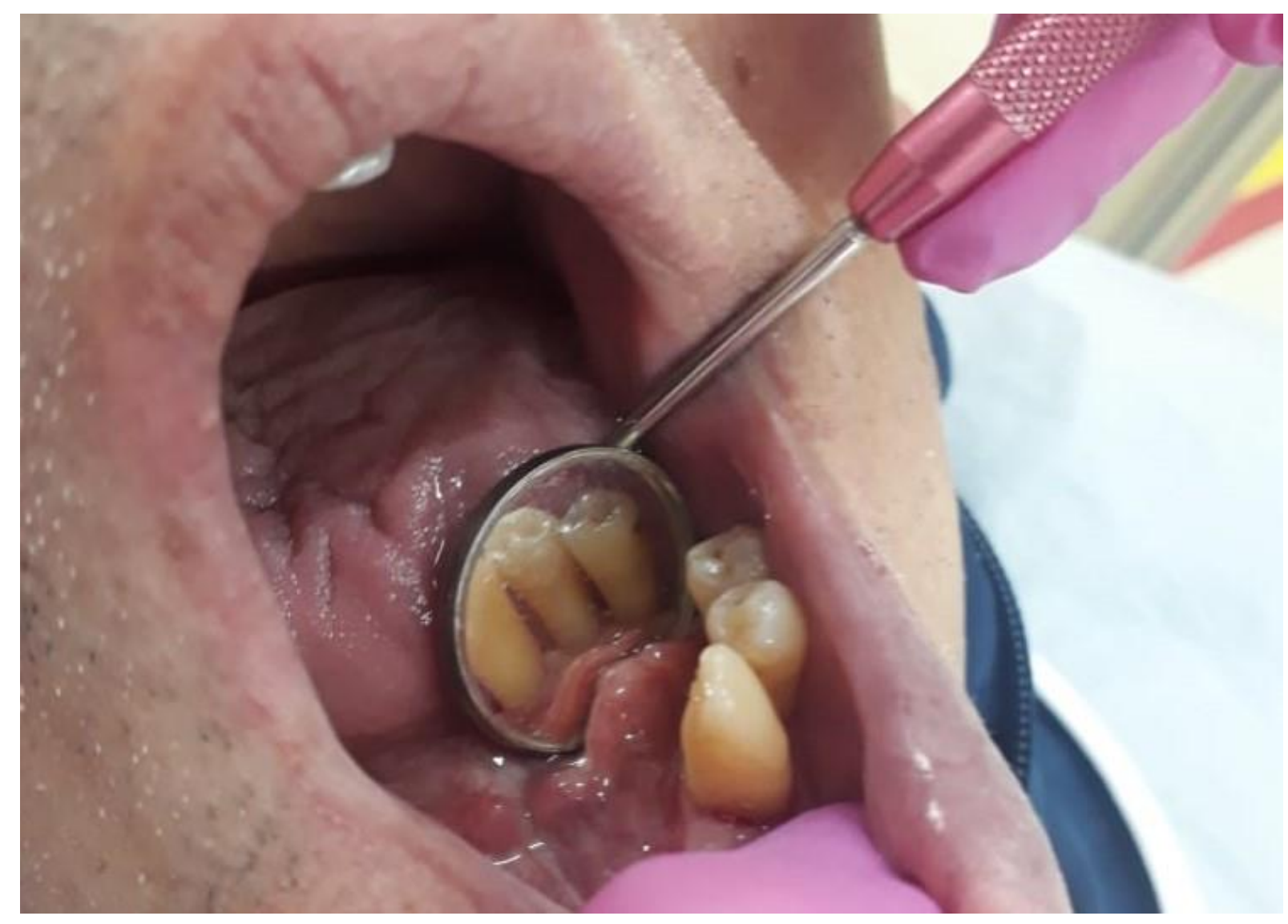

Fonte: Acervo do autor. 
llustração 6- Mesa clínica

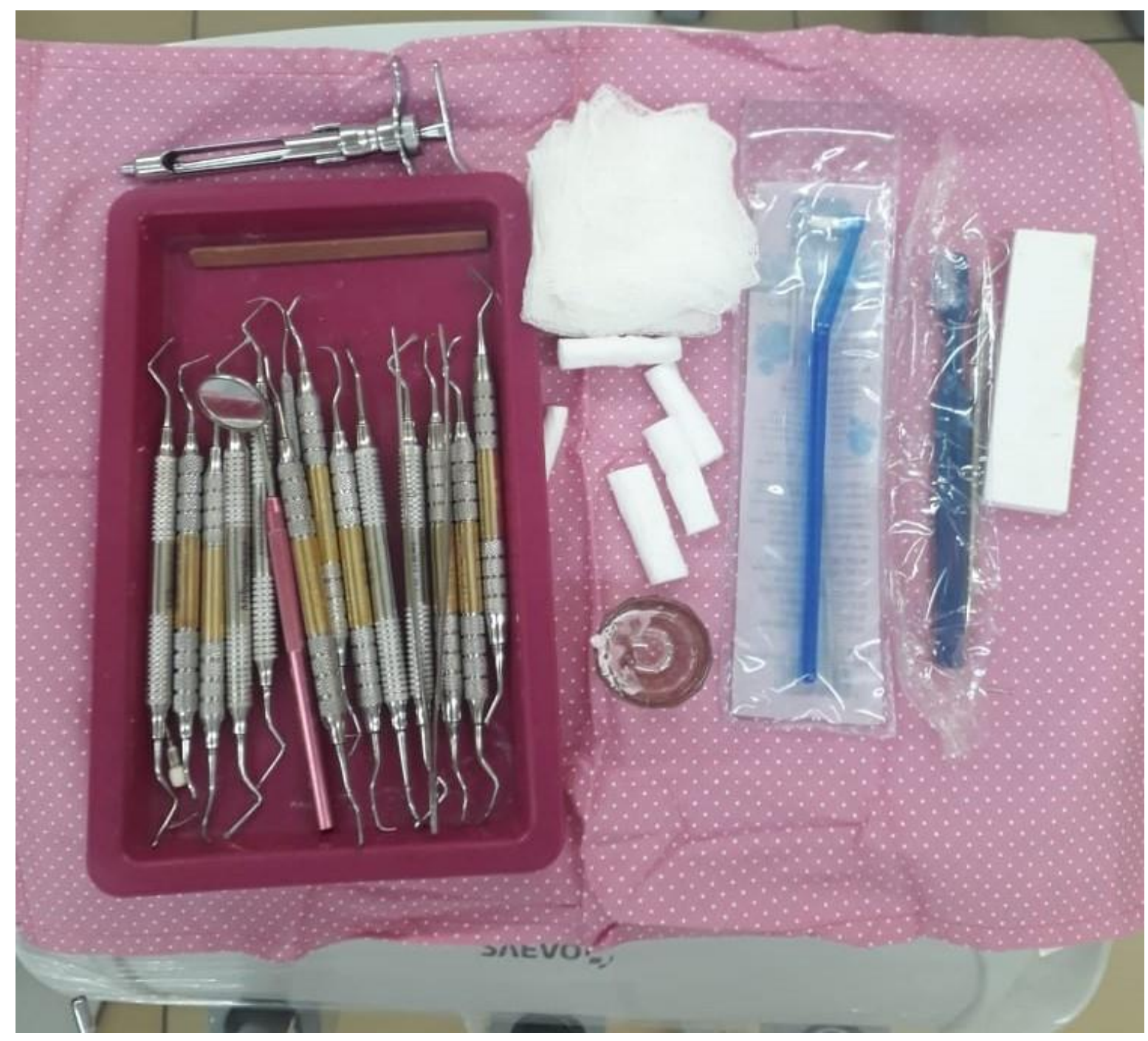

Fonte: Acervo do autor. 
Ilustração 7- Escovas dentais fornecidas para o paciente

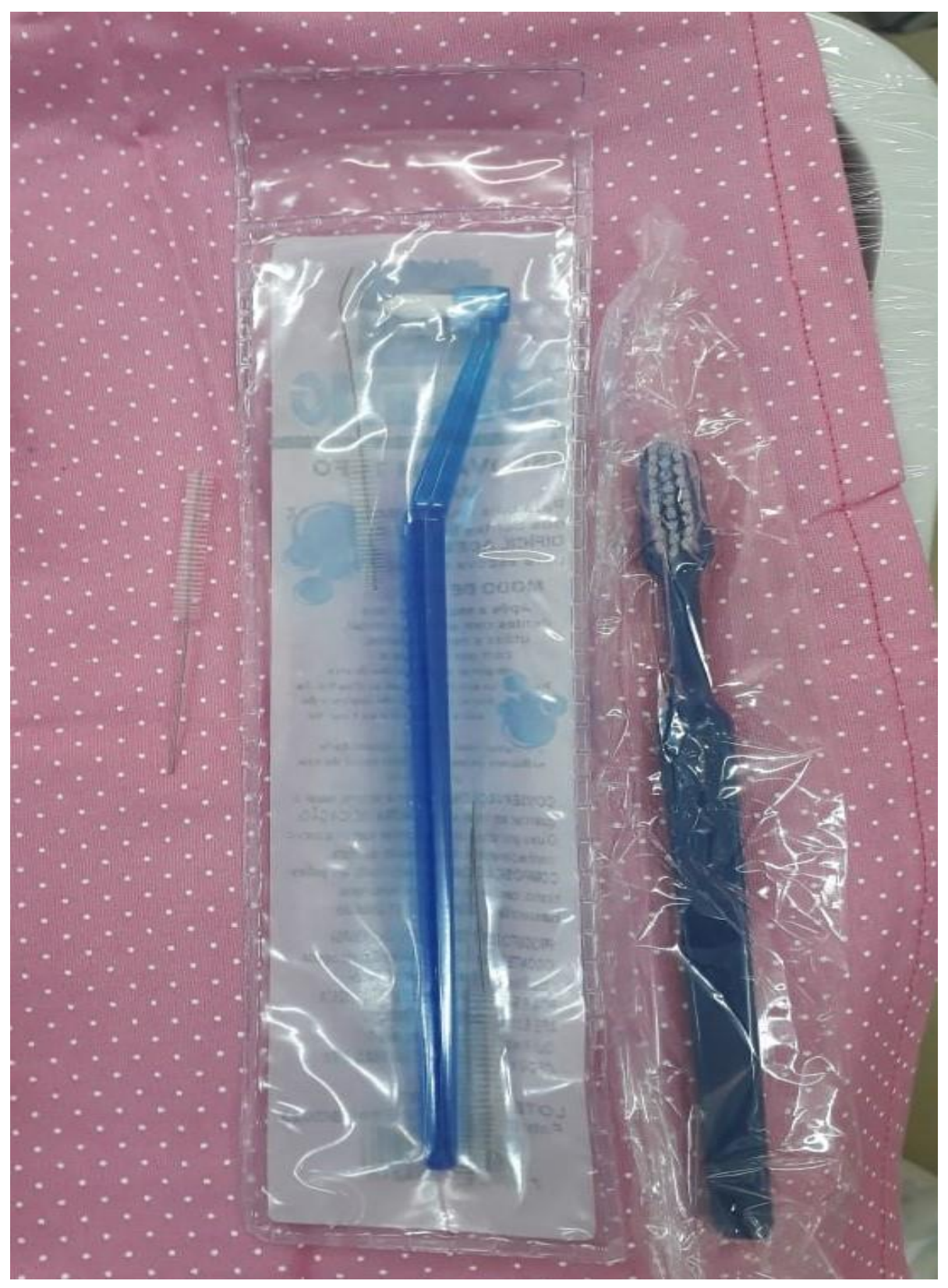

Fonte: Acervo do autor. 